\title{
SOBRE ETHOS E AD: TOUR TEÓRICO, CRÍTICAS, TERMINOLOGIAS
}

\section{(On ethos and discourse analysis (DA): theoretical overview, criticism and terminology)}

\author{
Melliandro Mendes GaLINARI
}

(UFOP)

Resumo: Neste artigo, busca-se abordar questões relativas ao ethos na Análise do Discurso $(A D)$, seja no sentido das "imagens de si" que o comunicante se constrói no presente de sua enunciação, seja enquanto as imagens partilhadas desse mesmo orador, pré-existentes a tal acontecimento discursivo. A partir de um rápido percurso conceitual, reflete-se criticamente sobre essas duas dimensões teóricas do ethos e sobre as terminologias usadas para designálas nas práticas de análise discursiva, a saber, as etiquetas "ethos pré-discursivo" e "ethos discursivo". Como se verá, prefere-se, aqui, por serem menos imprecisas, as expressões "ethos pré-corpus" e "ethos presente". Além disso, outras duas questões são abordadas: a interrelação das provas retóricas e a possibilidade de se estender o ethos às "imagens de outrem" construídas pelo discurso.

Palavras-chave: Ethos, Análise do Discurso, Retórica, Argumentação.

Abstract: The objective of this paper is to address questions relating to ethos in Discourse Analysis (DA), whether in the sense of "images of self" that the communicator constructs in the present of the enunciation, or regarding shared images of this same orator, pre-existing the discursive event. Based on a quick conceptual pathway, there is a critical reflection on the two theoretical dimensions of ethos and on the terminology used to designate them in discursive analysis practices, namely, the tags "pre-discursive ethos" and "discursive ethos". As will be seen, the expressions "pre-corpus ethos" and "present ethos" are preferred, as they are less imprecise. As well as this, another two questions are addressed: the interrelation of rhetorical tests and the possibility of extending ethos to the "images of others" constructed by the discourse.

Key-words: Ethos, Discourse Analysis, Rhetoric, Argumentation. 


\section{INTRODUÇÃO}

O conceito de ethos, que remonta à cultura grega antiga e às reflexões acerca da argumentação, tem sido resgatado de modo eficiente pela Linguística contemporânea, principalmente pela linha de pesquisa conhecida como Análise do Discurso (doravante AD). Depois de séculos e séculos, é notória e interessante a sensação de tal conceito ainda permanecer vivo (e operativo) para a análise da dimensão argumentativa dos variados discursos sociais. É por esses e outros motivos que, a seguir, passo a fazer algumas considerações sobre essa "ferramente teórica" - o ethos -, discutindo os seus aspectos conceituais e alguns possíveis encaminhamentos terminológicos. Permitir-me-ei, nesse ponto, fazer uma crítica (saudável, obviamente) a duas nomenclaturas a meu ver inconsistentes, a saber, as expressões "ethos discursivo" e "ethos pré-discursivo", bastante conhecidas e usadas indiscriminadamente sem qualquer contestação ou problematização. Em seguida, buscarei também ressaltar as relações de interdependência entre o ethos e as outras duas provas retóricas: o logos e o pathos.

Antes de tudo, gostaria de evidenciar que, ao falar de ethos, este trabalho o entende como parte de uma vasta engrenagem comunicativo-argumentativa, apreensível teoricamente por um conjunto de variáveis conceituais necessárias ao entendimento das interações cotidianas. Isso significa que o ethos está intimamente ligado a uma "moldura sócio-histórica" e a certas "circunstâncias de produção do discurso", emergindo sempre no interior de um "gênero discursivo" selecionado pelas mesmas e podendo gerar, juntamente com o logos e o pathos, várias modalidades de adesão: adesão a teses ("fazer-crer"), a ações ou comportamentos ("fazer-fazer") e a emoções ("fazersentir"). Esse quadro mais amplo sobre a interação retórico-discursiva, incluindo as variáveis teóricas necessárias à sua compreensão, foi colocado esquematicamente em Galinari (2009a), numa publicação disponível na internet. Ao falar de ethos, portanto, não perco de vista as informações ali presentes.

\section{O EтHOS}

Como já sabemos ad nauseum, "fazer-crer", "fazer-fazer" e "fazer-sentir" pelos predicados atrelados ao orador é lançar mão do que se convencionou 
chamar de ethos $^{1}$. Em termos gerais, trata-se da autoridade, do caráter e dos estatutos (os mais variados) atribuíveis à fonte enunciativa, que passariam a funcionar como "garantias simbólicas" para o sucesso da adesão ${ }^{2}$. Convencer/persuadir através do ethos constituiu-se, assim, num dos mecanismos centrais da atividade retórica. Para Aristóteles (1998:49), “(...) quase se poderia dizer que o carácter [ethos] é o principal meio de persuasão”. Destarte, a maneira como o orador se apresenta ao seu auditório, causando nele uma predisposição, poderia até mesmo dispensar os raciocínios mais elaborados, que caracterizam as argumentações centradas no logos em sua acepção demonstrativa. Diante do "bom ethos", a necessidade de uma demonstração lógica rigorosa perderia espaço para as três qualidades da condição persuasiva dos oradores: “(...) a prudência [phrónesis], a virtude [areté] e a benevolência [eúnoia]”. (Aristóteles 1998:106)

Nos tempos atuais, diversos pesquisadores têm procurado recuperar e (re)introduzir o conceito de ethos no âmbito da Análise Argumentativa do Discurso, num retornar constante às origens antigas. Assim, Plantin (2005:92) associa esse vocábulo a algumas expressões gregas, a saber: "a) le 'séjour habituel d'un animal'; b) 'caractère, la coutume, l'usage'; c) par extension, les 'moeurs"'3. De certo modo, o que se vê nessa citação acaba sendo algumas variáveis ethicas presentes no código moral de uma sociedade, que permitiriam a avaliação dos bons hábitos, costumes e qualidades exigidas do orador pelo seu auditório. Ressalto, então, a importância dos contratos, das convenções e das representações sociais para a adequada edificação e funcionamento do ethos, visto que a sua plausibilidade varia de comunidade para comunidade, de grupo para grupo, de indivíduo para indivíduo.

Outra significação (ou tradução) interessante para o ethos relacionase ao termo personagem. (Amossy 2006:70) Através dessa designação, um pouco teatral (ou literária), o ethos poderia ser entendido também como uma figuração subjetiva (um papel) dotada de estatutos morais e intelectuais, tornando-se uma espécie de "representação dramática" na vida simbólica

1. Considero, juntamente com Amossy (2006), a palavra orador em sentido amplo: ao usá-la, refirome, portanto, tanto à expressão oral quanto à escrita, individual ou coletiva/institucional.

2. Como se verá na seção 4 deste artigo, o ethos pode ser estendido teoricamente às "imagens de outrem", e não somente ao caráter daquele que cria/enuncia o discurso.

3. “a) o 'lugar habitual de um animal'; b) 'caráter, o hábito, o comportamento'; c) por extensão, os costumes”". 
cotidiana a serviço de possíveis modalidades de adesão (adesão a teses, a ações/comportamentos e a emoções, conforme mostrado em Galinari [2009a]). O orador-personagem seria, nessa perspectiva, a(s) imagem(ens) de si resultante(s) da performance discursiva, ou melhor, da atuação particular do locutor num cenário enunciativo. Por fim, mais uma leitura enriquecedora do ethos viria de Eggs (1999): o autor elabora uma revisão para os termos prudência (phrónesis), virtude (aretê) e benevolência (eúnoia), identificados por Aristóteles, no livro II da Retórica (trecho 1378a), como constituintes do caráter. Através do olhar de Eggs, esses termos são assim recolocados:

(...) les orateurs inspirent confiance, (a) si leurs arguments et leurs conseils sont compéténts, raisonnable et délibérés [prudência], (b) s'ils sont sincères, honnêtes et équitable [virtude] et (c) s'ils montrent de la solidarité, de l'obligeance et de l'amabilité [benevolência] envers leurs auditeurs ${ }^{4}$. (Eggs 1999:41)

Em termos gerais, essa variada rede de significações até aqui mostrada nos permite visualizar amplamente o ethos argumentativo: uma imagem de si, uma figuração (ou personagem) discursiva, uma distinção de caráter, de comportamento, de costumes etc. Entretanto, restaria deixar mais evidente - no contexto da $\mathrm{AD}$ - se esse conjunto de qualidades seria fruto de um conhecimento anterior acerca do orador, socialmente difundido e presente na coletividade numa complexa rede interdiscursiva, ou se seria um resultado construído no presente da enunciação, ou seja, no momento exato do desempenho oratório, seja ele oral ou escrito ${ }^{5}$. A partir de agora, procuro tratar desses problemas.

\subsection{Ethos "prévio", "interdiscursivo" ou "pré-corpus"}

É comum lembrar que, na abordagem aristotélica, o ethos vem tratado como uma persona engendrada pela palavra, no momento mesmo da palavra, o que dispensaria as imagens pré-existentes acerca do orador, anteriores à

4. (...) os oradores inspiram confiança (a) se os seus argumentos e seus conselhos são competentes, razoáveis e deliberados [prudência], (b) se eles são sinceros, honestos e justos [virtude] e (c) se eles se revelam solidários, prestativos e amáveis [benevolência] para com os ouvintes.

5. No caso da escrita, naturalmente, o momento exato da performance ou o presente da enunciação coincide com o ato da leitura. 
enunciação ${ }^{6}$. Entretanto, se queremos fundamentar a análise argumentativa nos moldes contemporâneos da $\mathrm{AD}$, o ethos deveria se estender, enquanto "ferramenta" de trabalho, às informações preliminares atribuídas ao sujeito comunicante. Isto porque, a princípio, podemos associar o ethos prévio ao nível situacional e/ou interdiscursivo da interação retórica. É nesse âmbito sócio-histórico, psicológico e cultural que se encontram, sob a forma de saberes partilhados, a reputação, a fama, os estatutos, as imagens ou as opiniões já conhecidas acerca do orador ou da instância de produção do discurso. O ethos passaria, assim, a contragosto do bom e velho Aristóteles, a não se restringir à dimensão linguística e particular do corpus estudado, abrangendo também a esfera dos dados situacionais, históricos e psicológicos que dizem respeito à instância de produção do discurso, reconstituíveis pelo acesso do pesquisador a um interdiscurso particular. Daí a pertinência de se falar, alternativamente, num "ethos interdiscusivo".

Ao resgatar essa dimensão "extracorpus" d do ethos, Amossy (2006) ancora-se nas reflexões de outros filósofos e pensadores, a começar por um contemporâneo de Aristóteles - Isócrates -, para o qual “(...) c’est la réputation préalable, le «nom » qui compte. Il ne s'agit pas de la façon dont il se donne à voir dans son discours, mais de ce qu'on sait déjà de lui" ${ }^{\text {. (Amossy }}$ 2006:71) Em sua pesquisa, a autora encontra conteúdos semelhantes nos escritos de Cícero, Quintiliano e outros, para os quais predominaria uma ética do bem viver, centrada nas bagagens pessoais, ancestrais e familiares dos oradores. Nos dias de hoje, essas reflexões acerca do ethos encontrariam ecos em conceitos modernos das Ciências Sociais, como a terminologia habitus, de Bourdieu, que desvincula o poder das palavras da estrutura linguística imediata para associá-lo, sobretudo, às experiências institucionais adquiridas e já conhecidas acerca dos indivíduos.

Assim sendo, com a designação ethos prévio (ou interdiscursivo, ou précorpus), a Análise do Discurso passa a considerar em sua epistemologia os elementos interdiscursivos na elucidação dos possíveis efeitos argumenta-

6. O próprio texto da Retórica o confirma: ao falar da confiabilidade advinda do caráter, isto é, do ethos, Aristóteles afirma que é necessário que “(...) esta confiança seja resultado do discurso e não de uma opinião prévia sobre o caráter do orador (...)” (Aristóteles 1998:49)

7. Utilizo a expressão "extracorpus" no lugar da usual "extralinguístico". A justificativa dessa troca terminológica encontra-se mais adiante, na seção 2.3 .

8. “(...) é a reputação prévia, o 'nome' que importa. Não se trata da maneira como ele se deixa ver em seu discurso, mas do que já se sabe sobre a sua pessoa”. 
tivos de um corpus particular, resgatando os estatutos sociais do orador (ou da instância de produção do discurso), a sua reputação, as suas qualidades morais, comportamentais etc ${ }^{9}$. Isso implicaria, também, ter consciência dos imaginários sociais que alimentam esses ethé, isto é, das representações coletivas, estereótipos, valores e outros tipos de saberes comuns cultivados (e em confronto) numa sociedade. Trata-se, mais uma vez, das variáveis simbólicas relativas ao universo sócio-histórico e situacional do discurso: a doxa. Seriam esses elementos que possibilitariam ao auditório avaliar as argumentações, de acordo com suas visões de mundo ou crença. Nas palavras de Amossy (2006:82), tais imaginários são construídos em torno de certas imagens:

- de l'image que l'on se fait de la catégorie sociale, professionnelle, ethnique, nationale, etc. du locuteur ;

- de l'image singulière qui circule d'un individu au moment de l'échange argumentatif ;

- de la possibilité d'images différentes, voire antagonistes, du même locuteur selon l'auditoire visé ${ }^{10}$.

Assim, se me é permitido construir um exemplo, o político-candidato poderia fazer-votar não pelas razões demonstradas num programa de governo (um logos mais imediato), mas, principalmente, pela sua (in)formação já conhecida/partilhada (economista, sociólogo, jornalista...) ou por certos estatutos acumulados em sua vida (homem do povo, sindicalista, ecologista...) avaliados pelos imaginários públicos, com suas suscetibilidades de influência, como ethé positivos para o exercício do poder. É nesse sentido que o ethos prévio se ligaria a uma (inter)discursividade ao redor do objeto analisado (outras formas de logos que não o corpus) e aos conhecimentos que os sujeitos falantes possuem a priori uns dos outros. Poderíamos até mesmo, por esse motivo, falar aqui em "ethos pré-corpus" ou "extracorpus". Mas, como

9. Assim, a terminologia ethos prévio só faria sentido com referência a um dado discurso posto como ponto de referência: o discurso analisado (ou seja, é prévio somente em relação a ele).

10. - da imagem que se faz da categoria social, profissional, étnica, nacional etc. do locutor; - da imagem singular de um indivíduo que circula no momento da interação argumentativa; - da possibilidade de imagens diferentes, ou mesmo antagônicas, do mesmo locutor segundo o auditório visado. 
veremos a partir de agora, essas características podem ser também fabricadas ou confirmadas pelo próprio discurso, no instante de sua realização.

\subsection{Ethos presente}

Antes de tudo, vale dizer que o sintagma "ethos presente", cunhado em Galinari (2007a) para substituir a expressão usual "ethos discursivo"11, simboliza uma certa fidelidade às formulações de Aristóteles, na medida em que vincula o ethos a um resultado da enunciação, no presente de sua ocorrência. De nada adiantariam, aqui, as boas e belas imagens prévias acerca do orador caso este não consiga atualizá-las no momento do seu discurso, ou caso o auditório não possua os meios (o domínio do código, os saberes comuns necessários, algum conhecimento etc.) para visualizá-las, na medida em que o interlocutor é um legítimo co-construtor dos sentidos. Por outro lado, pode-se acrescentar que o próprio presente enunciativo é capaz de destruir/desconstruir reputações solidificadas anteriormente, seja através: (i) de uma atuação oratória mal sucedida ${ }^{12}$ - e estou considerando tanto os textos orais quanto os escritos - ou (ii) da vontade do falante de se instituir como uma nova personagem ${ }^{13}$.

Portanto, o ethos presente é aquele que insurge de um logos bem específico e bem delimitado pelo pesquisador-analista, dadas as suas dimensões morfossintática, estilística e demonstrativa ${ }^{14}$. Em outros termos, trata-se das imagens de si presentes num dado corpus, recortado e estudado pelo analista, e relativo a um instante enunciativo particular. No caso dos proferimentos orais, pode-se acrescentar nesse âmbito outros fatores simbólicos importantes para a construção do ethos, como a expressão facial, o volume da voz, a encenação gestual, o tipo de vestimenta etc. Em estudos recentes, o ethos presente (chamado comumente de ethos discursivo) tem sido didaticamente caracterizado de duas formas: sobre o registro do mostrado e sobre o

11. A justificativa desta outra troca ou preferência terminológica encontra-se também mais adiante.

12. O que levaria o auditório a concluir: "ele (o orador) não é tão competente como se diz, ou como eu pensava desde o seu proferimento (ou escrito) anterior".

13. Que levaria o auditório a pensar: "ele mudou, é agora uma outra pessoa".

14. Ressalto, então, que a imagem de si resultaria do emprego discursivo de certos elementos linguísticos em detrimento de outros. O sujeito falante poderia se revelar, por exemplo, estilisticamente mais sério ou despojado, conforme a escolha lexical, as combinações sintáticas, os raciocínios e, também, os marcadores prosódicos, espaço das risadas, das pausas, do sotaque etc. 
registro do dito, o que depende do seu modo de manifestação na produção discursiva. (Maingueneau 1999)

No primeiro caso - referente ao ethos presente mostrado -, o sujeito do discurso se daria a entender com jogos de linguagem os mais singulares e/ ou discretos, sem precisar necessariamente dizer eu sou isso ou aquilo. Esse tipo de comportamento discursivo, ligado mais à aparência da enunciação do que ao conteúdo explícito do enunciado, muitas vezes é mais eficiente em termos de adesão, como nos indica o conhecido comentário de Ducrot (1984:201):

(...) il ne s'agit pas des affirmations flatteuses que l'orateur peut faire sur sa propre personne dans le contenu de son discours, affirmations qui risquent au contraire de heurter l'auditeur, mais de l'apparence que lui conferent le débit, l'intonation, chaleurese ou sévère, le choix de mots, des arguments... ${ }^{15}$

Portanto, conforme a ocasião, mostrar o ethos pode se tornar uma estratégia mais interessante do que dizê-lo, podendo provocar, concomitantemente, tanto um "efeito de naturalidade", quanto um "efeito de não arrogância". As autoatribuições elogiosas - referentes ao ethos presente dito - podem ser avaliadas, na maioria das vezes, como um comportamento discursivo arriscado, salvo se tais autodesignações são previstas/recomendadas pelo gênero ou por alguma convenção social ${ }^{16}$.

Dando prosseguimento ao assunto, foram colocados nas linhas anteriores alguns exemplos de como o ethos vem sendo utilizado pela Análise do Discurso, que o caracteriza duplamente seja como um elemento anterior à enunciação do corpus (caso da reputação e dos hábitos [ethos prévio]), seja como uma decorrência do presente enunciativo, isto é, da manifestação do discurso analisado (imagem mostrada ou imagem dita [ethos presente]). É necessário dizer ainda - e este é o ponto em que eu queria chegar - que a resultante persuasiva da argumentação acontece justamente a partir da inter-relação ethica entre informações prévias (ou interdiscursivas) e informações presentes (ligadas ao corpus estudado), admitindo-se tanto que o orador é capaz de

15. (...) não se trata de afirmações elogiosas que o orador pode fazer sobre a sua própria pessoa através do conteúdo do seu discurso, afirmações que, ao contrário, correm o risco de aborrecer o ouvinte, mas da aparência que lhe conferem a maneira de falar, a entonação calorosa ou severa, a escolha das palavras, dos argumentos...

16. Por exemplo, gêneros como autoavaliações, currículos e outros aceitariam como natural (ou menos artificial) menções elogiosas do próprio falante. 
"jogar" linguageira e dialogicamente com a sua "fama", no momento de sua enunciação (ampliando-a, recusando-a, modificando-a...), quanto o auditório é capaz de interpretá-lo às luzes do que já conhece sobre a sua pessoa (confrontando o que está ouvindo/lendo com as imagens já estocadas em sua memória acerca do mesmo orador, quando tal memória existe).

Nunca é demais relembrar que esse processo de influência é mediado por representações comunitárias acerca dos estatutos sociais apresentados na situação argumentativa, as quais têm o mérito de instaurar a validade ou a não validade dos ethé em questão. Desse modo, para que um candidatoeconomista (ou que se mostra/se diz entendido do assunto) seja aprovado, é necessário que os eleitores considerem, de alguma forma, essa "etiqueta" como algo adequado para o cargo postulado. Dito de outra forma, o funcionamento e a persuasividade do ethos liga-se também às características do auditório, ao seu poder de avaliar os objetos simbólicos e argumentativos apresentados pelo orador. Resta-me insistir, agora, no problema das nomenclaturas usuais.

\subsection{A questão terminológica}

Vale ressaltar inicialmente, afastando-me nesse pormenor das terminologias usadas por Maingueneau (1999) e Amossy (2006), que ambos os tipos de ethé - prévio e presente - são, na perspectiva aqui defendida, discursivos, ou seja, que eles brotam, de uma maneira ou de outra, de algum logos, seja daquele materializado no corpus recortado pelo analista, seja daquele(s) ligado(s) a uma (inter)discursividade anterior ou ao redor desse mesmo corpus, dispersa num dado contexto cultural em forma de saberes partilhados. O seguinte esquema resume o que acabo de dizer, questionando, o que é mais importante, as usuais terminologias "ethos pré-discursivo" e "ethos discursivo", a meu ver problemáticas e imprecisas do modo como são utilizadas pelos autores mencionados: 


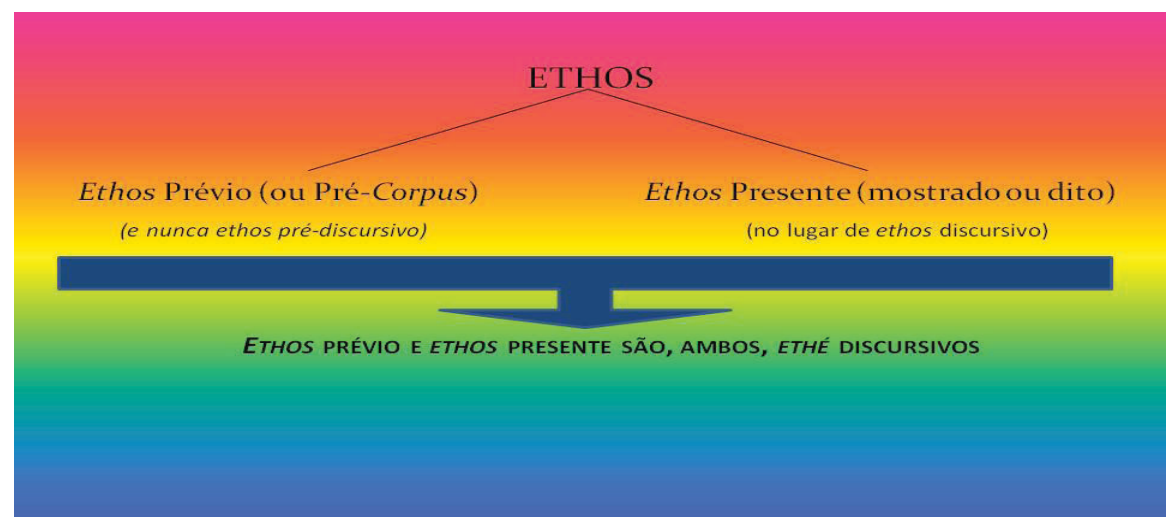

Figura 1: Ethos: esquema teórico.

Anaforizando: nunca ethos pré-discursivo! A imprecisão ou a impertinência dessa terminologia deve-se ao (óbvio) fato de que toda "imagem de si” ou ethos emana do uso da linguagem (verbal ou não), ou seja, dos bons e velhos discursos, e jamais de momentos míticos que os precedem, ou de recônditas e utópicas realidades "extralinguísticas", supostamente apartadas da linguagem. Essas palavras ou expressões de nossa ciência, com as quais estamos demasiadamente habituados, e muitas vezes sem qualquer lampejar de questionamento, podem não ser poucas. Nesse sentido, no mesmo campo semântico do famigerado "ethos pré-discursivo", deparamo-nos com o também esdrúxulo termo "extralinguístico". São, a meu ver, perfeitamente complementares na mesma imprecisão/confusão que buscam exprimir. É por essas e outras razões que seria também preferível substituir tal termo - "extralinguístico" - por qualquer outra coisa, como, por exemplo, por "extracorpus", mesmo que este não seja um vocábulo dos mais eufônicos, pois o referente em questão, principalmente no caso do ethos prévio, são imagens do comunicante oriundas de outros discursos, anteriores e/ou ao redor do corpus selecionado para a análise.

Sendo assim, aquilo que está fora do corpus ou do discurso analisado não poderia ser nunca algo extralinguístico (ou pré-discursivo, se nos referimos ao ethos): temos, sim, um interdiscurso significativo para a análise a ser empreendida, que perpassa, integra e dá vazão às suas respectivas realidades ou conjunturas. $\mathrm{Na}$ verdade, e insistindo, o que está fora do texto em foco (a dimensão extracorpus), são outros textos ou discursos que dão a ele - ao 
corpus - sentido, por constituírem situações comunicativas e contextos culturais mais amplos. Enfim, são “discursos prévios”, “já-ditos”, capazes de comportar variados ethé, e é nesse sentido que se torna preferível adotar expressões como "ethos prévio", "ethos interdiscursivo" ou "ethos pré-corpus" no lugar de "ethos pré-discursivo". As expressões aqui defendidas, enfim, teriam o mérito de indicar que o fato de algo preexistir a um objeto de estudo (discursivo, evidentemente) não significa ser ele da ordem do não discursivo. Passemos adiante.

No esquema já apresentado, como se viu, busco também criticar a expressão "ethos discursivo" quando esta designa aquela modalidade de ethos localizada em um discurso particular (um corpus), escolhido pelo analista e instituído como ponto de referência. Apesar de ser utilizada com frequência por vários teóricos de renome, acredito que seria mais recomendável usar a expressão "ethos presente". O termo "presente" aqui teria o mérito de irradiar uma dupla significação: (a) como adjetivo, refere-se a um ethos localizado (ou seja, "presente") no discurso analisado; (b) como substantivo associado à temporalidade, refere-se complementariamente a um ethos ligado ao "presente" temporal e situacional da enunciação desse mesmo corpus.

Enfatizando e resumindo a questão, enfim, as trocas terminológicas indicadas serviram para desfazer um mal-entendido e ressaltar que todo ethos é discursivo, seja ele anterior à enunciação do corpus estudado (ethos prévio/ ethos interdiscursivo/ethos pré-corpus), seja ele uma construção advinda do presente da performance oratória (ethos presente), uma vez que, seja de que maneira for, é ele um fruto da(s) linguagem(ns). Sem mais a dizer, passo a outro ponto teórico sobre o ethos.

\section{O ETHOS E AS OUTRAS PROVAS RETÓRICAS}

Esta parte do artigo busca refletir rapidamente sobre a inter-relação entre o logos, o ethos e o pathos, a sua importância teórica e a necessidade de maiores trabalhos sobre tal acontecimento, o que seria, acredito, proveitoso para as nossas análises discursivas e, também, para uma compreensão cada vez melhor do fenômeno retórico-argumentativo da influência. Como a temática principal é o ethos, este se encontra abaixo como o ponto de apoio da reflexão. 


\subsection{O ethos no logos}

Falar da relação entre ethos e logos é, usando o jargão popular, quase que "chover no molhado", pelo simples fato de que não teríamos ethos, e nem mesmo pathos, diante da inexistência do logos. Desde os antigos, este se define como o próprio discurso (com suas escolhas lexicais, operações sintáticas, componentes fonético/fonológico e prosódico etc.), incluindo as operações de raciocínio daí decorrentes (deduções, induções...). Dessa forma, o logos tornase aquilo que salta primeiramente aos olhos e ao entendimento, a saber, o nosso incontornável material linguístico-discursivo, podendo, por que não, ser conceitualmente estendido aos outros códigos semióticos. Em suma, é sempre a partir de um dado logos ou discurso (tanto oral quanto escrito), que o orador constrói o seu ethos ou, um pouco diferentemente, depara-se com a sua própria imagem construída por outrem. Pode-se afirmar, assim, que tanto o ethos quanto o pathos são desdobramentos semântico-retóricos do logos, ou seja, dois níveis de sentido profundos de sua estrutura em contexto, capazes de provocar a adesão em função das estratégias e suscetibilidades de influência das partes envolvidas na comunicação.

Em relação à apreensão do ethos no discurso, atividade por excelência do pesquisador em $\mathrm{AD}$, o desafio é saber como "pegar o boi pelo chifre", o que se traduz na seguinte problemática: quais são os elementos linguísticodiscursivos presentes no logos que nos permitem, durante a análise, acessar os ethé postos em cena pela enunciação? A resposta é muitos simples: em potencial, todos! Obviamente, em função do gênero de discurso, das condições de produção, dos seus atores sociais e convenções em jogo, certos elementos linguístico-gramaticais e raciocínios chamarão estilisticamente mais a atenção do que outros. Mas, a princípio, assim como o pathos, o ethos pode se revelar pelo uso de todo e qualquer elemento do logos: basta, durante a análise, e em função da conjuntura do discurso, estar atento a quais deles são mais dignos de nota. Vejamos alguns exemplos desses elementos, através de alguns recortes das várias dimensões possíveis do $\log 0 s^{17}$ :

- Os procedimentos e modalidades sintáticas: a ordem ou combinação das palavras/cláusulas, os tipos de relações interfrásticas ("coordenação" e "subordinação"), as funções sintáticas de base (a voz ativa/

17. As dimensões adiantes foram retiradas de Galinari (2011), texto destinado a apreender os significados possíveis de logos a partir da tradição sofística. 
passiva, a interrogação, a intimação [ordens, súplicas, pedidos...], as asserções [afirmações, certezas, definições...], as negações, as interjeições etc.).

- Os processos de formação de palavras (derivações, composições etc.); o vasto repertório (ou seleção) lexical: os indicadores da "pessoa" (os pronomes pessoais [eu, tu, ele...]), os indicadores da dêixis (pronomes demonstrativos, advérbios [ex.: isto, aqui, agora, isso, ontem, ano passado, amanhã etc.]), os fatores de modalização, como os adjetivos ou expressões adjetivas, os substantivos, os termos temporais (verbos, advérbios etc.), os conectores transfrásticos (que, entretanto, mas, contudo etc. $)^{18}$ e quaisquer outras classificações linguísticogramaticais.

- As representações, imagens ou visões de mundo criadas pelo discurso enquanto possibilidades semânticas de influência.

- A composição fonético-fonológica, ou seja, o material sonoro do logos.

- Os marcadores prosódicos (variações de tempo, de acento, de altura): o ritmo, a ênfase, a pausa, a entonação, a pontuação, o timbre da voz, as repetições etc. Inclui-se, assim, no logos, enquanto concretude semiótica do discurso, não só os elementos estritamente linguísticos, mas, também, as articulações paralinguísticas dos enunciados.

- Os raciocínios ou o modo lógico de organização do discurso (induções [exemplo], deduções [entimemas, silogismos], relações de causa e efeito, relações de contiguidade, relações de oposição, relações de proporcionalidade, analogias etc.)

- A estrutura narrativa do discurso

- A estrutura descritiva do discurso

- Os silenciamentos e pressupostos, se quisermos inserir o "não-dito" em nossa lista

18. Obviamente, os conectores transfrásticos estão ligados ao "logos-raciocínio", que se encontra também listado adiante. 
Temos, acima, portanto, algumas "chaves de acesso" e de interpretação do ethos a partir do logos. Trocando em miúdos, a dimensão argumentativa centrada no ethos edifica-se potencialmente através do uso das várias modalidades de logoi possíveis: "logos-palavra”, "logos-sintaxe”, "logos-fonéticofonológico”, “logos-prosódico”, "logos-raciocínio” etc. Não há espaço aqui, infelizmente, para ilustrar como cada uma dessas dimensões do discurso (ou do logos) poderia, na prática, construir ethé persuasivos. Isso demandaria muito mais laudas e o uso de variados corpora. Passo, então, a dizer algumas palavras sobre a relação do ethos com as emoções e com o pathos.

\subsection{O ethos no ato/tentativa de "fazer-sentir" e o pathos}

Certa vez, buscando precisar o conceito de pathos na análise argumentativa, afirmei que essa prova retórica englobaria todos e quaisquer aspectos linguístico-discursivos que, numa circunstância determinada, seriam capazes de desencadear no auditório algum tipo de reação afetiva. O pathos foi, portanto, considerado como uma tentativa, uma expectativa ou uma possibilidade contida nos discursos sociais, no sentido de despertar algum sentimento no alocutário. Nessa linha de raciocínio, o pathos não compreenderia propriamente as emoções, mas, sim, as suas garantias simbólicas ou, em termos linguísticos, os seus elementos linguageiros deflagradores. (cf.: Galinari 2007b:229)

Acredito, a partir daí, que falar da presença do ethos no pathos seria falar de uma coincidência, ou seja, da imagem que o sujeito cria de si diante do interlocutor enquanto está causando (ou tentando causar), nele, emoções pela via do logos/discurso. Obviamente, essa imagem de si ou ethos, dada como efeito possível do discurso numa conjuntura específica, só pode ser calculada em função do auditório e da possibilidade de especularmos ou sabermos o mínimo sobre os seus valores, intenções e suscetibilidades de influência. Só podemos analisar o ethos do sujeito que busca emocionar (no instante enunciativo dessa busca) tendo alguma idéia de como o auditório irá/tenderá receber, no calor da hora ou da leitura, tal apelo emocional: se emocionará junto com o seu orador e/ou será benevolente para com a sua causa se, munido de certos valores e posicionamentos, reconhecer nessa busca momentânea de "fazer-sentir" algo de legítimo, de verdadeiro ou de sincero; se revoltará ou será indiferente se, novamente através de suas crenças, concluir/sentir o contrário, taxando o orador, por exemplo, de 
"sensacionalista", de "demagogo" ou de "oportunista", posto que se trataria de um "fazer-emocionar" avaliado como fraude/engodo. Enfim, em função do auditório, de seus valores e dos elementos situacionais, o sujeito que se vale do pathos mostra, no desenrolar dessa ação oratória, um bom, mau ou indiferente caráter, que nada mais é do que uma possível dimensão etbica (dentre outras).

Em Galinari (2007b:235-237), tive, sob um outro prisma, a ocasião de também abordar esse fenômeno da inter-relação persuasiva entre o ethos, o pathos e as emoções. Reporto, aqui, a título de ilustração, o interessante dilema do "orador inflamado", de caráter ou ethos emocionado, que revela ou simula uma carga afetiva pelo logos/discurso. É importante salientar, nesse caso, que não se deve confundir os estados emocionais ocasionados no auditório com a afetividade expressa ou sentida pelo orador. A princípio, as paixões manifestas pelo enunciador não são da ordem do pathos, mas, sim, de um ethos emocionado. Nesse sentido, o interlocutor é confrontado a uma instância subjetiva incrementada por um status emotivo, advindo seja do ethos prévio, seja do ethos presente ${ }^{19}$. Porém - e vemos como a questão é paradoxal - se o "orador inflamado" contamina/contagia o seu auditório (ou é propenso a tal), fazendo-o compartilhar as sensações veiculadas, esse caráter emocionado pode muito bem ser encarado como um recurso do pathos, mas sem deixar de ser ethos. Encerrando este ponto teórico, vale dizer que exemplos dessa natureza mostram a complexidade da relação ethos/pathos/logos, dinâmica ainda pouco explorada pelas práticas correntes de análise argumentativa e, consequentemente, pouco relacionada às reais possibilidades de efeito de sentido. Vale reiterar, enfim, antes de passar adiante, que tanto o ethos quanto o pathos se constroem através do logos, ou seja, através de uma materialidade linguístico-discursiva.

\section{O ETHOS DE OUTREM}

Sem meias palavras, e já terminando, acredito que poderíamos construir análises discursivas destinadas a elucidar os "ethé de outrem", o que

19. Certos oradores, em determinado espaço social, são já bem conhecidos pela sua reputação emocional, traço marcante dos seus hábitos e costumes discursivos. Outros, isentos de tal "estigma", poderiam, por outro lado, produzir uma "vocalidade afetiva" inesperada, em momentos esporádicos das suas vidas oratórias. 
estenderia o ethos não apenas às imagens de si das instâncias de produção dos discursos abordados, mas também às imagens de seres/coisas ou instituições tematizados por esses mesmos discursos. $\mathrm{O}$ ethos, assim, não se resumiria, no plano teórico, ao conhecido jargão "imagens de si”, mas se estenderia também ao que poderíamos chamar de "imagens de outrem". Extensão teórica legítima? Bem ou mal, é o que acontece no Elogio de Helena, do lendário sofista Górgias, e, em geral, em discursos de caráter epidíctico, que têm por objetivo o elogio ou a censura (ressalte-se: de outrem). O exemplo do Elogio gorgiano é claro: poderíamos falar, a partir dessa obra, de uma "bifurcação ethica": de um lado, ali está o ethos de Górgias enquanto a instância produtora do discurso (uma "imagem de si"), e, de outro, o ethos de Helena, que não passa de uma figura tematizada pela obra, ou melhor, um elemento terceiro (uma "imagem de outrem") ${ }^{20}$. Algum tempo depois da sofística gorgiana, Aristóteles, ao iniciar seus ditos sobre o referido gênero epidíctico, parece ter reconhecido essa possibilidade teórica do ethos, o que chamo aqui de "ethos de outrem". Vejamos um trecho da Retórica:

(...) falemos da virtude e do vício, do belo e do vergonhoso; pois estes são os objectivos de quem elogia ou censura. Com efeito, sucederá que, ao mesmo tempo que falarmos destas questões, estaremos também a mostrar aqueles meios pelos quais nós deveremos ser considerados como pessoas de um certo carácter. Esta era a segunda prova [ou seja, o ethos]; pois é pelos mesmos meios que poderemos inspirar confiança em nós próprios e nos outros no que respeita à virtude. (Aristóteles 1998:75) (grifo meu)

Não é difícil reconhecer a possibilidade, nos ditos de Aristóteles, de construirmos o caráter ou ethos dos outros em nossas enunciações, assim como construímos o nosso próprio caráter. Aliás, o fazemos pelos mesmos meios, ou melhor, pelas artes do logos. Indo mais além, construímos conscientemente ou não o nosso ethos ao mesmo tempo em que elogiamos ou denegrimos alguém, visto que marcamos um certo posicionamento ou revelamos um traço da nossa personalidade (por exemplo, pode "soar bem" ou "mal" dizer algo negativo ou positivo sobre outrem). Interrogando melhor, já não seriam os ethé prévios ou pré-corpora nada mais do que imagens de outrem do orador, que circulam "à boca pequena” em dada comunidade sob a forma de saberes partilhados? Enfim, o que se está postulando aqui seria estender ao ethos os estudos acerca das representações sociodiscursivas.

20. Em relação ao ethos no Elogio de Helena e outras questões argumentativas, ver Galinari (2009b). 
Em outras palavras, trabalhos como aqueles que elucidam, por exemplo, a "imagem do negro" na publicidade, a "imagem da mulher" nas propagandas de cerveja ou as "representações de Brasil" na imprensa estrangeira, são trabalhos que, admitindo-se ou não, lidam com uma outra faceta teórica do ethos, a saber, o ethos como "imagem de outrem/algo/alguém”. Deixando a questão em aberto, passo, finalmente, às últimas palavras.

\section{CONSIDERAÇÕES FINAIS}

Procurei ressaltar acima a importância do ethos nas análises discursivas, uma vez que, sabemos, as imagens de si criadas pelos falantes e pelas instituições sociais constituem-se, desde que o homem é homem, como algo imprescindível para o sucesso e para a deflagração da influência. Podemos, assim, falar tanto de um ethos da pessoa física (RG/indivíduo), se buscamos elucidar as estratégias do "Cláudio" ou da "Maria" etc., quanto de um ethos da pessoa jurídica (CNPJ/instituição). Esta última possibilidade abre caminhos para estudos bem complexos e interessantes, por nos permitir trabalhar com os ethé dos partidos políticos, das igrejas ou religiões, das empresas de mercadorias e serviços etc., o que levanta também a questão da "palavra delegada" ou "designada", ou seja, daquele que fala em nome da instituição. Deixando tais questões à margem, preferi neste artigo insistir na questão terminológica, justificando a impertinência de expressões bastante conhecidas (ethos pré-discursivo e ethos discursivo) e substituindo-as por outras que julguei serem mais precisas (ethos pré-corpus [ou extracorpus, ou prévio, ou interdiscursivo] e ethos presente). Deixei, enfim, para reflexão, dois pontos que merecem ser mais estudados e levados em consideração durante as análises discursivas: a questão da inter-relação das provas retóricas (ethos, pathos e logos) e a possibilidade de estendermos à categoria de ethos as "imagens de outrem" presentes nos discursos.

Recebido em abril de 2011 Aprovado em janeiro de 2012 E-mail: melliandro@yahoo.com.it 


\section{REFERÊNCIAS BIBLIOGRÁFICAS}

Amossy, Ruth. 2006. L'argumentation dans le discours. Deuxième édition. Paris: Armand Colin.

Aristóteles. 1998. Retórica. Lisboa: Imprensa Nacional - Casa da Moeda.

Ducrot, Oswald. 1984. Le dire et le dit. Paris: Minuit.

EGGS, Ekkehard. 1999. Ethos aristotélicien, conviction et pragmatique moderne. In: Amossy, Ruth. (sous la direction de) Images de soi dans le discours: la construction de l'ethos. Genève: Delachaux et Niestlé. p. 31-59.

Galinari, Melliandro Mendes. 2011. A Polissemia do Logos e a Argumentação. Contribuições Sofísticas para a Análise do discurso. EIDEA - Revista Eletrônica de Estudos Integrados em Discurso e Argumentação. Ilhéus: UESC, v. 01. Disponível em: http://www.uesc.br/revistas/eidea/>. Acesso em: 21/06/2012.

. 2009a. A Interação Retórico-Discursiva e suas Múltiplas Variáveis. Revista de Estudos da Linguagem, Belo Horizonte: FALE/UFMG, v. 17, n. 2. Disponível em: < http://relin.letras.ufmg.br/revista/upload/172_08.pdf $>$. Acesso em: 02/03/2011.

. 2009b. Logos, Ethos e Pathos no Elogio de Helena: Relações entre a Sofística e a Análise do Discurso. In: II Encontro Memorial do ICHS, 2009. Anais online. Mariana: DELET/ICHS/UFOP. Disponível em: $<$ http://www.ichs.ufop.br/memorial/trab2/1432.pdf $>$. Acesso em: 02/03/2011.

. 2007a. A Era Vargas no Pentagrama: dimensões político-discursivas do canto orfeônico de Villa-Lobos. Tese (Doutorado em Linguística) Faculdade de Letras, UFMG, Belo Horizonte. Acesso em: < http:// www.dominiopublico.gov.br/pesquisa/DetalheObraForm.do?select_ action $=$ \&co_obra $=83004>$. Acesso em: 02/03/2011.

. 2007b. As Emoções no Processo Argumentativo. In: Machado, Ida Lúcia.; Menezes, William Augusto; Mendes, Emília. As Emoções no Discurso. Rio de Janeiro: Lucerna. p. 221-239.

Maingueneau, Dominique. 1999. Ethos, scénographie, incorporation. In: Amossy, Ruth (sous la direction de). Images de soi dans le discours: la construction de l'ethos. Genève: Delachaux et Niestlé. p. 75-100.

Plantin, Christian. 2005. L'argumentation: histoire, théories e perspectives. Paris: PUF. 